that the changes in urinary-oestrogens excretion after oophorectomy or adrenalectomy cannot be related to clinical benefit. ${ }^{6}$ A possible conclusion is, therefore, that the benefit that follows oophorectomy or adrenalectomy in some patients with breast cancer is due not so much to removal of oestrogen as to the consequent liberation of gonadotrophins that follows such ablation therapy.

In other words breast cancer in the younger woman may not be so much "oestrogen dependent" as "pituitary dependent." 7 There is, of course, other evidence that points to the same conclusion, but I hesitate to repeat this evidence in a letter. I would add only that my suggestion should lead logically to a trial of human pituitary gonadotrophin administration in patients with breast cancer failing to respond to castration. A similar trial was suggested in the treatment of cases showing a low gonadotrophin excretion after adrenalectomy. ${ }^{8}$ The absence of reports of such trials in the literature to date reflects the difficulty of procuring adequate supplies of human pituitary gonadotrophin for therapeutic trial, but I hope that this will be remedied in the near future.-I am, etc.,

Melbourne, Australia.

BAsil A. Stoll.

REFERENCES

Segaloff, A., Gordon, D., Carabasi, R. A.,
Horwitt, B. N., Schlosser, J. V., and Murison, P. J., Cancer (Philad.), $1954,7,758$.

Loraine, J. A., Douglas, M., Faliconer, C. W. A., and Strong, J. A., Acta Un. int. Cancr., 1959,

$15,1132 . \dot{E} . \mathrm{F} .$,
Scowen, and Hadfield, G., Cancer

Douglas, M., Falconer, C. W. A., Strong, J. A., and Loraine, J. A., In Human Pituitary Gonawell, Oxford.

5 Poulain, S., Dargent, M., Mayer, $M_{\text {., and }}$ Pommateau, E., Abstracts of Papers, Moscow , p. 199. Medgiz Publishing House, Moscow.

Bulbrook, R. D., Greenwood, F. C., Hadfield, G. J., and Scowen, E. F., Brit. med. 7., 1958,

'Stoll, B. A., In Modern Trends in Endocrinology, ed. $H$.

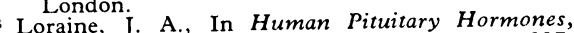
C.I.B.A. Foundation colloquia 13, 1960, p. 237 . O'Connor, Churchill, London.

\section{Drugs for Depression}

SIR,-YYour leading article (29 August, p. 522) on "Drugs for Depression" requires some comment.

Firstly, you promulgate the "pseudoscientific" myth that depressions can be divided into endogenous and reactive types, in spite of the formidable researches of Lewis $^{1}$ and Garmany. ${ }^{2}$ We $^{3}$ have reinvestigated this problem in Edinburgh and found only two factors which were clearly discriminatory, severity of depression and history of previous manic episode. We feel, therefore, that using the dichotomy endogenous-reactive as a basis for differing drug therapies is misleading. Your contributor goes on to mention Drinamyl (dexamphetamine and amylobarbitone) as an efficacious agent in the treatment of depressive symptoms occurring in the context of a personality problem. This seems surprising in 1964, when we know that amphetamine is highly addictive ${ }^{1}$ and that it can readily cause toxic psychoses. ${ }^{5} \quad$ Then there is reference to iproniazid as "still the most effective" of the monoamine oxidase inhibitors, without adequate reference to the appreciable mortality from liver damage. ${ }^{6}$ Finally, in the last paragraph there is the suggestion that nortriptyline has a strong sedative effect, but has "not yet been adequately assessed." I presume, Sir, that your contributor had not had the opportunity of reading the recent issue of the Scottish Medical fournal in which our evaluation of nortriptyline is reported. ${ }^{7}$ We found this drug to be more effective, on the sample of depressives treated, than amitriptyline, and also markedly less sedative. In fact, we found nortriptyline to have a quite definite antidepressant or stimulant effect more akin to that of imipramine.

It may seem presumptuous to question your leading article this way, but it will be read by many general practitioners who treat many of their depressive patients themselves and will regard your leader as authoritative. In this field, where the effect of the doctor is often as great as that of the drug, it is not wise to be dogmatic. ${ }^{8}$ Nevertheless, it may be justifiable, taking severity of deprestion as the criterion, to suggest the following rank order of antidepressant drugs. For severe depressions, imipramine is generally accepted to be first choice, and, if our experience proves to be any guide, nortriptyline may well become second choice. For moderate depressive reactions, especially where agitation is prominent, amitriptyline with its marked sedative effect is indicated. For milder depressions, especially where anxiety and phobic symptoms are present, the combination of phenelzine and chlordiazepoxide is a good treatment regimen. ${ }^{10}$ Tranylcypromine may be used in small dosage-that is, $10 \mathrm{mg}$. b.d.-in special cases, and iproniazid in the very exceptional case, though personally I regard it as too toxic. It is my opinion, and the opinion of many psychiatrists in this region, that amphetamines should never be prescribed for depressive illnesses.-I am, etc.,

\section{Royal Edinburgh Hospital.
Morningside, Edinburgh.}

\section{REFERENCES}

1 Lewis, A. J., f. ment. Sci., 1934, 80, 277.

Garmany, G., Brit. med. F., 1958, 2, 341. Brit. F. Psychiat., 1964, in press. Kiloh, L. G.

1962, 2, 40. H., Amphetamine Psychosis, Maudsley Monographs No. 5, 1958. Chapman

and Hall, London.
West. E. D., and Dally, P. J., Brit. med. f., $1959,1,1491$.

Forrest, A. D., Affleck, J. W., Gibb, I. A.
McL., and Priest, R. G., Scot. med. f., 1964, 9, 341 .

Rickels, K., f. nerv. ment. Dis., 1963, 136, 540. Sheard, M. H., ibid., 1963, 136, 555. Sheard, M. H., ibid., 1963, 136, 555.
Sargant, W., and Dally, P., Brit. med. F., 1962,
1, 6.

\section{Ampicillin for Typhoid Carriers}

SIR,-I read with obvious interest Dr. K. F. Anderson's letter (29 August, p. 571) in which he criticizes my earlier letter on the treatment of typhoid carriers with ampicillin (9 May, p. 1252). His letter raises many points of undoubted interest but I would like to confine myself to a few comments.

I am surprised that Dr. Anderson's experience has been limited to cases in which there was "obvious gall-bladder disease with one or more calculi present."

My experience, in accord with many others, includes a large number of cases in which no such pathology was present. Christie's ${ }^{1}$ series of eight faecal carriers included four with normal functioning gall-bladders and no evidence of stones.

The object of my letter, however, was not to discuss the aetiology and pathology of the carrier state but briefly to report on what seemed, and indeed still seems, to be a very encouraging response to a new antibiotic in patients who had previously resisted all chemotherapy.

Whatever our later investigations into these patients' serology may show in the way of Vi-antigen titres, the fact remains that the excreta of these previously persistent carriers has now remained free of salmonellae for a period of from 18 months to two and a half years, and as such they are unable to trigger off a new outbreak of typhoid fever.

No one would disagree with Dr. Anderson that caution should be exercised before assuming permanent cure of these patients, nor would anyone deny the need for surgery when indicated.

To infer, however, that the reporting of such dramatic changes in the excretion pattern of chronic carriers should await the interpretation of long-term serological investigations of questionable significance reveals surely a failure to appreciate the clinical problem.-I am, etc.,

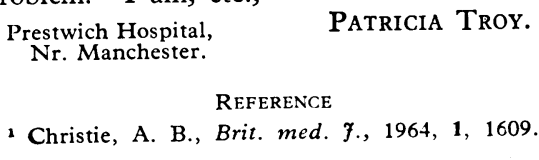

\section{Pargyline Hydrochloride}

SIR,-In your leading article "Drugs for Depression" (29 August, p. 522) you say: "Tranylcypromine (Parnate) is the only monoamine-oxidase inhibitor that is not a hydrazine." As far as antidepressive drugs are concerned this statement is true. We would, however, like to remind you that pargyline hydrochloride (Eutonyl), which is intended for the treatment of hypertension, is also a non-hydrazine monoamine-oxidase inhibitor.

Until the introduction of pargyline hydrochloride monoamine-oxidase inhibitors were mainly intended for use in the treatment of depression, and it is important to remember that here we have an antihypertensive which requires the same precautions as regards cheese, yeast extracts, alcohol, etc. It is possible to avoid these reactions, and for this reason we have made available instruction cards for patients which list the dietary and other restrictions involved.-I am, etc.,

Abbott Laboratories Ltd.,

J. S. Munro.

\section{Arteriospasm after Ergotamine Tartrate}

SIR,-Dr. E. Byrne-Quinn's memorandum (29 August, p. 552) prompts me to report a similar case recently admitted to University College Hospital.

The patient is a 59-year-old woman, admitted 18 months previously with non-thrombocytopenic purpura, the cause for which was obscure. Since then she had had about three attacks of headache accompanied by visual disturbance suggestive of migraine. The last attack began one week before admission. Four days later Cafergot- $Q$ tablets (containing $1 \mathrm{mg}$. ergotamine tartrate) were prescribed. She took three of 
these during a 24-hour period, and her headache improved, but the same day severe pain began in both ankles and feet, and the next day she was unable to walk.

On admission she was normotensive, and febrile ( $99.5^{\circ}$ F. ; $37.5^{\circ}$ C.). Apart from a soft pansystolic apical murmur, abnormal signs were confined to the legs. No pulses could be felt below the femorals, and there was a sudden temperature drop at both mid-calves. The distal parts of both feet were pale, ischaemic, and very painful.

The ischaemia was attributed to intolerance to ergotamine with presumed underlying obliterative arterial disease. The legs were exposed and kept cool, and tolazoline, $25 \mathrm{mg}$. thrice daily, given by mouth.

For two days there was little change, but on the third day both feet were warm, red, and oedematous, and later all pulses became readily palpable. The feet remained painful for several days, but there was no gangrene and the patient was eventually discharged home free from signs and symptoms in the legs.

There was no evidence of obliterative arterial disease or renal disease. The flocculation tests were weakly positive and the sedimentation rate $62 \mathrm{~mm}$. at one hour falling to 32 , but there was no increase of gammaglobulin on serum electrophoresis and no other evidence of an underlying collagen disease.

This case was considered to be a further example of prolonged arteriospasm after oral ergotamine tartrate for supposed migraine, in the absence of the recognized contraindications, but in this case due to intolerance to modest dosage $(3 \mathrm{mg}$.) rather than to overdosage with ergotamine.

I wish to thank Dr. Kenneth Harris for permission to report this case.-I am, etc.,

University College Hospital

$$
\text { R. A. L. Sutton. }
$$

London W.C.1.

\section{Drug Rash After Triprolidine}

SIR,-I was very interested in Dr. Suzanne L. Alexander's letter (22 August, p. 512). I have not seen the eruption she describes after using Proactidil but her letter strikes a chord. Grant Peterkin first described a lichenoid eruption occurring in troops in the Middle East who were given mepacrine to suppress malaria. ${ }^{1}$ I came across it in troops in the Far Eastern theatre of war on the same therapy. It was then labelled "tropical lichenoid dermatitis". Since then I have seen the same eruption following the use of mercury (Guy's Pill), gold (Myocrysin) and even phenobarbitone. It is possible that many other drugs produce this reaction in certain individuals and perhaps triprolidine now adds its name to this list.-I am, etc., Allan Bighaim.

REFERENCE

1 Peterkin, G., and Hair, H. C., Brit. F. Derm.,
}

\section{Longer Training for Radiographers}

SIR,-We, the undersigned radiographers, do not agree with Mr. R. F. Farr (18 July, p. 191) that lengthening the course from two years to three would encourage recruitment. Most women hope to be married early, and with this in mind the. relatively short two-year training is attractive. If the training had lasted three years we would not have been so attracted to radiography as to other threeyear courses. Nor do we agree that a threeyear training would be better than a two-year course followed by a hospital appointment for one year, or that women would be more likely to stay in radiography having done a three-year course. Few leave it now except for marriage or for the same work abroad.

The effect of lengthening the course would be serious in the transitional year: (1) at hospitals not recognized as suitable for thirdyear students, vacancies which under present conditions would be filled by newly qualified radiographers would not be filled at all; (2) at hospitals recognized as suitable the vacancies would be filled by third-year students not allowed to take full responsibility or to do unsupervised night duty, which would result in more night duty for the qualified radiographers. After the transitional year the effect is unpredictable. So many potential recruits may be deterred by the three-year course, as we would have been, that the radiographer shortage may become worse.

The present arrangements are working reasonably well. Why risk changing them ? -We are, etc.,

London N.W.3. Pamela J. Wheldon.

SIR,-I am constrained to comment on the inconsistent nature of Dr. G. Osborne's letter (5 September, p. 630) regarding the training of radiographers. He writes: ". . . the more advanced techniques tend to be left to the more senior radiographers . . .," and, discussing the bulk wastage of females on marriage, ". . this is a reason for letting students start at 17 and qualify at 19 . . . "

How does one acquire senior staff under these circumstances? Or again, if one implements the author's theory that males be excluded from the profession because of an unattractive salary range, where else can one muster experienced assistance ?

Two principal issues arise from this: (1) Wouldn't the profession be a more stable and enlightened body with the continuing addition of senior male members ? (2) How does one form a cadre of experienced radiographers when recruiting stems only from the female population?

Surely it would be to everyone's advantage to discourage the "poor risk" element, and to increase the salary and the training period to encourage the "better risk" (and potentially senior) prospects.

For the interest of my colleagues this is no calumny on the good name of the senior and experienced female radiographer.-I am, etc.,

Welwyn Garden City,

Hertfordshire.

\section{G. F. HURST.}

\section{T.A.B. for European Travel}

popular press (at least in The Times of 4 September), will worry them more than ever.

I can assure you, Sir, that the travelling public is not the healthily confident body it once was, but comes only too readily for medical advice before crossing the Channel. Each summer term brings me a bigger crop of students asking for advice or demanding immunization (which is quite often unnecessary) before travelling to other European countries. Some members of the academic staiff are no better. Surely each case should be considered individually, and to recommend a universal measure, which in itself is not without risk and discomfort, is wrong. Need we have the national hypochondria on this aspect of travel boosted by those who should know better ?-I am, etc.,

University College of Swansea, T. C. DANN. Glamorgan.

\section{Umbilical Cord}

SIR,-Y Your leading article on the umbilical cord (1 August; p. 264) makes very interesting reading.

You rightly point out that " the cause of foetal death when the cord prolapses may be vascular spasm as well as direct pressure." I wish you had laid emphasis on the former factor more strongly. I have no doubt that vascular spasm in the cord is often the primary cause of foetal death in these cases, ${ }^{1}$ apart from the fact that it can account for a misleading non-pulsatile cord when the foetus is still alive. Vascular spasm is elicited by cold and by handling; hence the correct management in prolapse of the cord is to replace it gently into the warm vagina. Further handling of the cord may be dangerous.

On the point of cord entanglements, one might draw attention to the fact that this finding in the case of twins is characteristic of a mono-amniotic set. ${ }^{23}$ If the second twin is to be saved delivery must be immediate. -I am, etc.,

$$
\begin{aligned}
& \text { Medical School, } \\
& \text { St. Luke's Hospital, } \\
& \text { Malta. }
\end{aligned}
$$

\section{A. P. Camilleri.}

\section{REFERENCES}

1 Rhodes, P., Proc. roy. Soc. Med., 1956, 49, 937. Bender, S., and Prebble, S. E., Brit. med. F., 1961, 1, 1810. Amer. F. Obstet. Gynec., 1961,

\section{Hierarchies in Mental Hospitals}

SIR,-Most psychiatrist will have sympathy for Dr. C. Entwistle's wish (5 September, p. 631) to do away with hierarchism in mental hospitals. Some will find his solution-abolition of the office of medical superintendent or director-naive. He apparently hopes that by abolishing an office he can abolish abuse of power. Reflection on human nature suggests he may be over-optimistic. Consultant rulers of small empires can be as authoritarian as superintendent rulers of large.

Dr. Entwistle has not followed the golden SIR,-Your expert's reply on " T.A.B. for European Travel " is alarming (5 September, p. 621). Can he really mean that all travellers to all European countries, whether staying in cities or in the country, should be immunized against typhoid and paratyphoid? Already people are over-sensitive about typhoid after the recent outbreak in Aberdeen, and now your expert's reply, quoted in the neglects to ask-if there are, as he states, authoritarian medical superintendents-why, since the Mental Hospitals Act of 1959, do consultants acquiesce in this state of affairs? Could it be that such consultants are as hierarchy minded as their "ruler"- and wish for themselves authority which they resent in rule of diagnosis before prescription. $\mathrm{He}$ 